\title{
The Prima/Ultima Facie Justification Distinction in Epistemology
}

THOMAS D. SENOR

The University of Arkansas

\section{Introduction}

The distinction between prima facie and what is sometimes called 'ultima facie' justification in epistemology is familiar. Yet I believe that its importance is generally under-appreciated. This distinction is extremely useful in making clear the demarcations between competing epistemological theories. I begin this paper by discussing the primary motivation for recognizing this distinction, and then enumerate the ways that it sheds light on the foundationalist/coherentist, internalist/externalist, and naturalism debates in contemporary epistemology.

\section{Marking the Distinction}

The primary reason to make the distinction between prima and ultima facie justification is to make a place for epistemic defeasibility. The need for an account of defeasibility arises from the recognition that there are two rather different ways of having unjustified beliefs. One's belief might be unjustified because one bases one's belief on either bad reasons or no reasons. Let me briefly describe three cases that will serve as paradigms in the discussion that follows:

Case 1: Chuck believes that Mary doesn't like chicken because they were once at a restaurant together and Mary ordered lamb when she could have had chicken.

Case 2: Alice looks across the quad (in good light) and sees in the distance a person she takes to be her colleague Ed. She comes to believe that she sees Ed. However, Alice also (justifiably) believes that Ed is in France and will not return to the U.S. for another six months. 
Case 3: Buck wonders if there is a lectern in the room in which he is about to teach. Buck opens the door to the class, turns on the light, and sees a lectern on the table that is 10 feet in front of him. Buck comes to believe that there is a lectern in the room.

There is nothing particularly noteworthy or interesting about these cases. Nevertheless, they can be used to illustrate three rather different epistemic situations. In the first case, Chuck forms an unjustified belief about Mary's culinary preferences. His belief is unjustified because it is poorly grounded. There are many other, more plausible explanations of Mary's ordering lamb besides the hypothesis that she doesn't like chicken (which is at best a partial explanation). In this case, then, his belief is unjustified because it is not properly grounded. ${ }^{1}$

Case 2 represents an alternative way that a belief can be unjustified. Alice's belief is well-grounded in that it is based on a visual experience of the sort that generally provides her with good (reliable) evidence for standard perceptual beliefs. However, this case is one in which the good evidence she has for her belief is undercut by other propositions she believes. In the end, she is unjustified in her belief. Yet there seems to be an important difference between this case and Case 1. In this second case, had other things been equal (i.e., had she not believed that Ed was out of the country), she would have been justified in believing that she had seen Ed. On the other hand, there is very little to be said for beliefs formed in the first manner.

Cases of this second sort are best described by invoking a distinction between prima facie and ultima facie justification. Because Alice's belief is well-grounded, her belief is prima facie justified. Yet since its justification is defeated by her belief that Ed is in France, it fails to be ultima facie justified. This allows us to distinguish between cases (a) in which a belief is poorly grounded and completely unjustified, (b) in which one has justification that is defeated, and (c) in which there is undefeated justification. ${ }^{2}$ So Case 2 is an example of a belief that is prima facie justified but which fails to be ultima facie justified. ${ }^{3}$

1 I should note here that although epistemic grounding is thought by many epistemologists to have a causal (or at least counterfactual) element, one who denies such accounts can still regard a belief as properly or improperly grounded. A ground can be understood as the state(s) that the person takes to be her reason for her belief.

2 John Pollock distinguishes between two sorts of defeaters, viz., undercutting and rebutting. Loosely, a rebutting defeater for the belief that $p$ is a reason to think that $p$ is false; an undercutting reason for believing $\mathrm{p}$ is a reason for believing that one's ground for believing that $p$ is unreliable. See Pollock (1986), pp. 38-39.

3 A referee points out that it is a consequence of the $\mathrm{p} / \mathrm{u}$ distinction as I make it that one can be simultaneously prima facie justified in believing a proposition and prima facie justified in believing its negation. Indeed, Case 2 should be read this way. 
An important issue arises here. What constraints should one place on the kinds of beliefs that function as defeaters? For example, can a belief that is not conscious at $t$ function as a defeater at $t$ ? Or must all defeaters be conscious when doing their epistemic damage? ${ }^{4}$ Perhaps a more plausible condition would require a defeater to be either conscious or readily accessible, i.e., easily introspectible. An even more significant issue concerns the epistemic status of the potential defeater. Must a defeater be justified itself in order to defeat the justification of another belief? Or is it enough that the defeater simply be believed? Quite obviously, what one decides on these questions will have significant consequences for one's account of justification. Since it is not the purpose of this paper to plump for any particular epistemological theory, I'll be able to leave these matters for another time. However, let me say that it is very plausible to suppose that there is more than one important notion of epistemic justification, and that the concept one is analyzing will determine (at least in part) the way one answers the above questions. For example, one explicating an verific externalist concept of justification might well hold that a defeater must be justifiably believed but need not be readily accessible to introspection. A belief that is not verifically justified will do nothing to indicate that another of the subject's beliefs is not likely to be true. On the other hand, a perspectival internalist might well claim that a defeater need only be believed, i.e., that it needn't be prima facie justified. Additionally, the perspectivalist is likely to insist that a defeater be either conscious or at least readily accessible to consciousness. One concerned with a notion of justification which has at its root the internal perspective of the agent (i.e., how the world looks to her) might well claim that having a belief $q$ that entails or makes highly probable that not-p gives one a defeating reason not to believe $\mathrm{p}$ as long as one is aware of $\mathrm{q}$, aware that $\mathrm{q}$ entails (makes probable) not-p, and lacks a meta-belief to the effect that one's belief that $q$ is unjustified or poorly grounded. ${ }^{5}$

Case 3 requires little discussion. It is an example of a belief that is wellgrounded and the justification for which is not defeated. Its purpose is to make clear that Case 2 is intermediate between cases in which there is no justification at all and one in which the justification remains perfectly in tact.

These examples provide us with a useful way to mark the prima/ultima facie distinction (hereafter the 'p/u distinction').

See Pollock (1986), pp. 46-58.

Another neglected issue of great importance for the theory of justification concerns the range of the theory. Are the items to which justification applies beliefs simpliciter or the more restricted class of conscious beliefs. One who thinks that the theory of epistemic justification is simply a theory about the conditions under which conscious beliefs are justified will be much more inclined to restrict defeaters to conscious beliefs. On the other hand, if one thinks that stored, non-conscious beliefs are sometimes justified, one will be inclined to think (I would suppose) that stored, non-conscious beliefs could function as defeaters. 
PFJ: A belief is prima facie justified iff it bears the appropriate relation to a state or process that will make the belief ultima facie justified if there is no other state or process relevant to the justificatory evaluation of the belief. ${ }^{6}$

This account is intended to be a schema for theories of prima facie justification rather than a substantive theory. As far as I can tell, PFJ is compatible with every standard account of justification. It leaves as an open question the nature of epistemic justification (thus PFJ is congenial to evidentialists, reliabilists, holists, and even contextualists) as well as the relationship a belief must bear to the justifying state or process (thus PFJ should be accepted both by those who accept and those who reject causal/counterfactual accounts of the basing relation).

One should not take the p/u distinction to be making a temporal or sequential claim. That is, it is tempting to understand prima facie justification to be that which the agent has before the justification for the belief is defeated or that which one has until one's evidence gathering is complete. But this is to misunderstand the nature of the distinction. Let's think again of Case 2 . As I am construing the $\mathrm{p} / \mathrm{u}$ distinction, Alice is prima facie justified and not ultima facie justified from the moment that she forms the belief. What a defeater defeats, on this view, is ultima facie justification.

It might help to note that a belief's being prima facie justified is nothing other than its having its justification 'other things being equal.' We might as well call prima facie justification 'ceteris paribus justification.' 7 Were it not for the fact that the former terminology is already imbedded in the current literature, I would suggest using the latter term as it is more exactly right. What distinguishes prima facie from ultima facie justification isn't usefully put as the former's being justification 'on the first look' but rather justification 'other things being equal.'

Finally, it is important to see that prima facie justification shouldn't be identified with the third condition of the neo-traditional JTB+-a-Gettier-defeating-condition account of knowledge. Of course, one might have a theory that equates them, but the two are not conceptually identical. For example, one could construct a very plausible theory of justification according to which defeaters for justification must be internal states of the believer. One could then have very well-grounded true belief, not have a justification defeater among one's belief (and perceptual) states, and hence have ultima facie justification but still lack knowledge if the external situation is Gettierized.

6 I take it that even the negative coherentist can adopt PFJ since she can take a maximally loose interpretation state or process that does the justifying. I owe this point to Richard Lee. 
It is time for me to make good on my claim that this distinction can be exploited for the purpose of making sharp the differences between competing theories.

\section{Foundationalism, Coherentism, and Reliabilism}

In this section, I will demonstrate how the p/u distinction can be of use in clarifying both the foundationalist/coherentist debate and the nature of process reliabilism. In discussing reliabilism in the same section as foundationalism and coherentism, I run the risk of being misunderstood. I do not think that reliabilism is best construed as a direct competitor of either of these views. The foundationalism/coherentism debate is concerned with the structure of justification; reliabilism is a theory of the nature of this epistemic property. ${ }^{8}$ Most of this section will concern the former issue, with a discussion of reliabilism being used to as a segue into the following section on the internalism/externalism controversy.

A theory of justification is foundationalist only if it divides our justified beliefs into two sorts, basic and nonbasic. An epistemically basic belief is a belief that is justified but not in virtue of its relation to other beliefs; an epistemically nonbasic belief is justified in virtue of bearing the right kind of relationship to other justified beliefs. Furthermore, it is an important component of foundationalist theories that at least some degree of the justification for epistemically nonbasic beliefs must somehow trace back to epistemically basic beliefs. Usually, this condition can be understood as implying that every proposition that is essential to the justification of nonbasic belief must either be itself the content of an epistemically basic belief or must be the last link of a chain of justified beliefs whose first link is an epistemically basic belief. ${ }^{9}$

8 I realize that not everyone will agree with this. Nevertheless, I think that the best way to construe the issue between the foundationalist and the coherentist is as a disagreement about the structure of justification. There are times when substantive theories of justification are known simply by the labels 'coherentism' or 'foundationalism', but I would prefer to use these terms for theories of justificatory structure. For example, BonJour is clearly a 'structural' coherentist, but the theory that he offers in BonJour (1985) is a substantive account of the nature of justification. This account is a form of the substantive theory I'll call 'epistemic holism.'

Of course, it might turn out that the theory of the nature of justification one accepts constrains the theory of the structure of justification one accepts. For example, as a referee pointed out when commenting on an earlier version of this paper, it is hard to see how to combine reliabilism with coherentism. I agree and it might be that one can demonstrate that the theories aren't in the end compatible. If that were the case, then coherentism and reliabilism would be indirect competitors, 'indirect' because they are theories of different analysanda.

9 For the purposes of this discussion, I am assuming that the strength of justification afforded a basic belief is sufficient for a belief's being justified; it is not also necessary that the belief also be supported by other beliefs the subject holds. 
There is a fundamental divide among foundationalist theories. More traditional varieties (e.g., that of Descartes) are infallabilistic "all the way down." That is, they claim that (a) a belief is epistemically basic only if it is infallibly held and (b) a nonbasic belief is justified only if it is the logical consequence of epistemically basic beliefs. Typically, infallibilist foundationalism has also insisted that the subject be aware that she holds the belief in this epistemically maximal manner. Infallabilistic foundationalists believe that defeating the skeptic is a key desideratum of their epistemological program; this can be accomplished, they suppose, only if the truth of an infallibly held justified belief is in an important sense transparent to the subject. Because of their insistence on infallibility and what we might call 'truth transparency,' infallibilists have neither need of, nor place for, defeasibility. A belief that is infallibly held and whose truth is transparent is a belief for which the subject has indefeasible justification.

Fallibilist foundationalism comes in two varieties. First, some have held that while epistemic basicality requires infallibility, the transfer of justification requires only that the inferred belief be made probable by the beliefs from which it is inferred. ${ }^{10}$ The second type of fallibilist foundationalism is currently much more common. This foundationalism requires infallibility for neither the foundations nor for the transfer of justification. Since this is the more popular (and plausible) of the two fallibilist foundationalisms, henceforth when I discuss fallibilist foundationalism, it will be this thesis to which I refer.

Being a much weaker thesis, fallibilist foundationalism is open to fewer objections than is its infallibilist cousin. Blinded by this glaring advantage, many foundationalists have seen no reason to defend infallibilism, believing that fallibilist versions of foundationalism can provide most of the advantages of the traditional theory without generating any serious difficulties or requiring important concessions to the foundationalist's arch rival, the coherentist. ${ }^{11}$

The coherentist believes that there are no privileged beliefs, that no belief is justified except in virtue of the relations it bears to other beliefs. Thus, the coherentist denies the fundamental claim of the foundationalist, viz., that epistemic justification is fundamentally dependent on a set of beliefs that are justified independently of the relationship they bear to other beliefs. While coherentism can be defined as simply the thesis that there are no privileged beliefs and that only beliefs can function as justifiers, I believe that there are other descriptions of the position that paint more accurate pictures of coheren-

$10 \quad$ E.g., see Lewis (1946).

11 The one potentially important loss in moving from infallibilism to fallibilism is the chance of refuting the skeptic. However, since most contemporary foundationalists are dubious, to say the least, that such a refutation is in the offing, this loss is seen as minimal. 
tist theories that are actually held. The coherentist is typically an epistemic holist. He believes not so much that all justification is inferential, but that justification is a function of the fit between a particular belief and the agent's entire doxastic corpus. A belief is justified only if it coheres to a belief system that is itself coherent. He rejects the foundationalist linear conception of justification, preferring instead a 'network' perspective.

The foundationalist's move away from infallibilism does a great deal to blur the originally sharp distinction between her theory and coherentism. To see this, recall that the infallibilist foundationalist does not have to concern herself with defeasibility. Since only infallibly held beliefs are epistemically basic and since only deductive transfer relations are countenanced, epistemic defeat is impossible. A belief is justified if and only if it is either infallibly epistemically basic or else derived (by chains of obvious, valid inferences) from infallible beliefs. What this means is that the infallibilist can state unequivocally that an epistemically basic belief's justification is independent of its epistemic relations with other beliefs, and that the justification of a nonbasic justified belief depends solely upon the inference upon which it is based. Thus the claim of the holistic coherentist can be absolutely rejected; nothing of justificatory significance hangs on global epistemic relations.

Things are rather different for the fallibilist foundationalist. Since, on her view, a belief's justification is no guarantee of its truth, justification of even epistemically basic beliefs is defeasible. What this means is that the fallibilist is not in a position to unequivocally state that the justification of an epistemically basic belief is independent of its relations to other beliefs. For the justification of a basic belief can be defeated by other members of the subject's doxastic system. Rather than being locked out of fallibilist foundationalism, as it is with the infallibilist variety, epistemic holism has its foot in the door. And, of course, a similar point can be made with respect to the justification of nonbasic beliefs. The justificatory status of a nonbasic belief is not solely dependent upon the justifying argument upon which it is based. Rather, the belief will be justified only if it is both supported by a licensed inference and doesn't conflict with beliefs ${ }^{12}$ elsewhere in the system; again, a holistic element has been introduced. So it turns out that the move from infallibilist to fallibilist foundationalism carries with it a more significant cost than first appeared. According to the latter theory, no justified belief is epistemically independent of the subject's entire doxastic corpus. This is a rather important concession to the coherentist.

The fallibilist foundationalist can magnify the difference between her theory and coherentism by exploiting the p/u distinction. She can recast the

12 As discussed earlier, the foundationalist might wish to restrict defeaters to prima facie justified beliefs. Even so, an element of holism has been introduced to the foundationalist picture. 
terms of the foundationalist/coherentist debate as a disagreement over the structure of prima facie justification; she can claim that foundationalism captures the structure of prima facie rather than ultima facie justification. In order for a belief to be prima facie justified, she will claim, it must either be epistemically basic or be inferred from other justified beliefs. ${ }^{13}$ For even the fallibilistic foundationalist can assert unequivocally that an epistemically basic belief's prima facie justification is independent of the subject's other beliefs. Holism is wholly absent from this component of the theory.

Given that any plausible theory of justification will have to include some no-defeater clause, it is reasonable to think that the real theoretical battleground on which the foundationalism/coherentism war is fought should be that of prima facie justification. Thus, I don't believe that altering the terms of the debate does anything to denigrate the importance of the issue.

While applying the p/u distinction to fallibilist foundationalist theories is pretty straightforward, it might appear that the distinction is not at home among coherentists. This can be seen by again considering the foundationalist. She says that a belief is prima facie justified iff it is of a privileged kind or it is justifiably inferred from other justified beliefs. Any nonbasic belief that is not part of an inference upon which a belief is based is not relevant to its status as prima facie justified. ${ }^{14}$ The coherentist, by contrast, is holistic about prima facie justification. That being the case, one might wonder if he can have anything but a trivial no-defeater clause. For either a belief coheres with the doxastic system or it doesn't. If it does, then it is prima facie justified, but it is hard to see how that justification could be defeated by anything else in the system since if it were, the belief wouldn't cohere with the system, so contrary to our hypothesis, it wouldn't be prima facie justified in the first place. On the other hand, a belief not cohering with the system apparently entails that it fails to be prima facie justified by the coherentist's account.

13 It is an interesting question, which I will not try to settle here, whether the foundationalist should require only that a justifying belief or set of beliefs be prima facie justified or whether ultima facie justification is necessary in order for one belief to make another prima facie justified.

14 Here, as elsewhere in the paper, I'm ignoring the possibility of a mixed view according to which a belief gets some of its epistemic support from inference (or from whatever it is in virtue of which it is epistemically basic) and some from cohering with the doxastic system. Such views are possible, and are such that the $\mathrm{p} / \mathrm{u}$ distinction applies to them, but considering them needlessly complicates the present paper.

I should also note that in the preceding two sentences in the text, I have written as though the foundationalist must hold that justifiers are limited to that upon which a belief is based. There are many foundationalists who hold no such thing (e.g., Roderick Chisholm (1989), and Richard Foley (1987)). However, the point I'm making in the text is one that they would also accept; I word things as I do only for the sake of simplicity. 
I believe that this dilemma is only apparent. The coherentist can employ the p/u distinction by putting flesh on the following theory-schema: S's belief $B$ is prima facie justified iff it bares coherence relation $R$ to a belief subsystem with characteristics $\mathrm{C}$. As it stands this tells us rather little. The coherentist will have to spell out in some detail what the coherence relation (R) is (something he'll need to do in any case) and, more to the point at hand, give an account of the properties that a belief subsystem must have in order for a belief that coheres with it to be prima facie justified. So a coherence theory can account for defeasibility, and hence make the p/u distinction, by claiming that prima facie justification is the result of a belief's cohering with an appropriate subsystem within the subject's overall belief system. This would allow the coherentist to claim that ultima facie justification is what one has when one's belief coheres with one's entire doxastic system or at least with every part to which the agent has access. Thus, the p/u distinction is at home with coherentism after all. While I don't mean to suggest that giving content to $\mathrm{C}$ in the above schema is an easy task, it is necessary if the coherentist is to account for epistemic defeasibility. And if coherentism is to be plausible it must allow for defeasibility.

Thus, the p/u distinction can be used to bring the foundationalist/ coherentist debate into clearer focus. ${ }^{15}$ Similarly, it can be useful in making clear the claims of the process reliabilist.

In his now classic paper, "What is Justified Belief?"16, Alvin Goldman offers the following first pass at reliabilism much like the following:

PR: $S$ is justified in believing that $P$ iff ' $S$ 's belief that $p$ is produced and sustained by a reliable cognitive process.

There are well-known counterexamples to this simple analysis, some presented by Goldman himself in the very paper in which he introduces his theory. This isn't the place to discuss such examples in detail, but I will need to briefly explicate one of them. The example is designed to show PR does not provide a sufficient condition of justification. Consider a man, Jones, who has been presented with overwhelming evidence that his apparent memories of childhood events are wholly misleading, that he has suffered a form of amnesia that results in his episodic memory of his early years being erased and replaced with apparent memories that bear no significant relation to events of

15 There is one other way that the fallibilist foundationalist can continue to insist that there is a principled difference between her position and that of the coherentist: she might attempt to distinguish positive and negative support. That is, the foundationalist will say that holistic concerns are not relevant to concerns of positive support, but come in to play in a negative way only. While this way of dealing with the coherentist challenge is moderately successful, it leaves the foundationalist in the position of needing to offer a clear demarcating the positive from the negative. 
his early years. Despite the strength of the evidence that his memory is unreliable, the evidence is misleading; in fact, Jones' memory is very good, even for events that took place in his youth. Suppose that Jones has an apparent memory of his having a party in celebration of his seventh birthday, and that he comes to believe that he did have such a party. Goldman grants that Jones is not justified, and includes a no-defeater clause in his theory of justification. Goldman's theory is, in the end, not a thorough-going externalist theory because an agent's background beliefs can defeat her justification. So as long as his theory is taken to be a theory of justification simpliciter (or even of ultima facie justification), Goldman is neither a pure reliabilist nor a pure externalist.

I believe that Goldman would have been better off adjusting the analysandum rather than the analysans of his theory. That is, instead of adding the nodefeater clause as part of his account of justification simpliciter, he should have said that the case of Jones serves to remind us of the importance of including an account of defeasibility as a part of one's theory of ultima facie justification; however, PR should be understood as an account of prima facie justification. Thus, the necessary and sufficient condition expressed in PR stands as it is; what gets changed is the analysandum. This move has the advantage of keeping the focus on the essence of the account. As I claimed earlier, everyone will have to include a no-defeater clause of some kind so it is implausible that such clauses are the primary points of difference between competing theories of justification. Indeed, competing theories are likely to differ in their accounts of the no-defeater condition inasmuch as they differ in their accounts of prima facie justification. Because the heart of the theory will be the account of prima facie justification, Goldman's best move in light of the counterexample to a reliabilist sufficient condition would have been to maintain the sufficiency of reliable belief-production for prima facie justification. His account of this crucial epistemic property could then have remained unrepentantly reliabilist and externalist.

We will now turn our attention to the internalist/externalist debate.

\section{Internalism and Externalism}

Unlike the foundationalist/coherentist controversy, there has never been a generally agreed upon way to distinguish internalism from externalism. And while I suspect that there must be a fair amount of stipulation when making such a dichotomy, I believe the p/u distinction can be useful here as well.

Internalists typically stress the importance of the perspective of the epistemic agent. Thus, the sense of internal that is particularly appropriate here is more than physical or even psychological. For there are many states that are internal in each of these senses but which for all that aren't accessible to the agent. Hence, the relevant notion of internality here is epistemic: a property 
is epistemically internal iff one can come to know by introspection (or justifiably believe) that one instantiates it. Let's further note that there are two importantly different kinds of internalist conditions: positive and negative. A positive internalist condition requires that the agent have accessible to her a reason for thinking that the belief in question is true or reliably held or justified; a negative internalist condition requires only that the agent not have access to a reason to think the belief is false or unreliably held or unjustified.

The externalist, on the other hand, is less concerned with perspectival considerations. Externalists hold that the property that confers justification need not be one to which the agent has any sort of access. The skeletal version of process reliabilism considered above is the very paradigm of an externalist theory.

Having already discussed the way that the p/u distinction can be useful in one central epistemological debate, I can rather quickly employ it here. I suggest that what is really at issue between internalists and externalists is prima facie justification. The reason for this is simple: where the issue is ultima facie justification, there is no controversy; some form of internalism is surely correct. To see this consider again PR and the ensuing discussion. Goldman himself grants that his theory of justification requires a no-defeater clause. But a no-defeater clause for a theory of justification will be (or at least entail) a negative internalist condition; every theory of justification of which I'm aware allows that justified beliefs can function as defeaters. ${ }^{17}$ So process reliabilism, construed as a theory of ultima facie justification, includes an element of internalism. However, if we understand PR as a theory of prima facie justification, it is devoid of internalist conditions. Similarly, when we look at traditional internalists, it is clear that their view is not simply that there is an internalist constraint on ultima facie justification, but rather on prima facie justification as well. To take but one quick example, Roderick Chisholm takes internalism to be a thesis that "merely by reflecting upon [one's] own conscious state, [one] can formulate a set of epistemic principles that will enable him to find out, with respect to any possible belief he has, whether he is justified in having that belief." 18 This is an internalism with a vengeance. But notice that even the rather mild internalism that one finds in William Alston's work is best construed as a condition on prima facie justification. Alston's view is that in order for a state $\mathrm{J}$ to justify $\mathrm{S}$ 's belief that $\mathrm{P}, \mathrm{J}$ must be 'fairly readily accessible' to $S .{ }^{19}$ If one cuts the pie as I am suggesting,

17 This is even true of the account of justification found in Goldman (1979). For although Goldman attempts give an account of defeasibility in terms of alternative, available, reliable processes, the case of Jones discussed above is a case in which a justified belief of Jones's serves as a defeater; the explanation of why this belief defeats Jones's justification is in terms of alternative available processes.

19 See "An Internalist Externalism" in Alston (1989), pp. 227-48. 
then what makes Alston an internalist is this condition and not the nodefeater clause included in his view. Thus, I suggest that any view that requires an positive internalistic constraint on prima facie justification be construed as internalist and any theory that doesn't require such a constraint is externalist. Hence the following:

Internalism: J provides $S$ with prima facie justification for believing $\mathrm{P}$ only if $\mathrm{J}$ is internally accessible to $\mathrm{S}{ }^{20}$

Externalism: It is not necessary that $\mathrm{J}$ is internally accessible to $\mathrm{S}$ in order for $\mathrm{J}$ to provide $\mathrm{S}$ with prima facie justification for believing $P$.

On this way of cutting things up, externalism is simply the denial of internalism. The externalist is not one who insists that, necessarily, only external factors are necessary and sufficient for justification. While he might be committed to the claim that as a contingent truth, those factors responsible for justification are inaccessible, he should not be regarded as claiming that this truth is necessary, either conceptually or metaphysically. A reliabilist would not become in internalist if he were to suddenly become convinced that we do have access to the reliability of our cognitive processes. ${ }^{21}$

\section{Naturalizing the Epistemic}

Naturalism in epistemology comes in a number of varieties. As far as I can tell, the p/u distinction is relevant to only one, viz., semantic epistemological naturalism. Semantic epistemological naturalism is the thesis (or set of theses) that epistemic terms, concepts, and properties are to be explicated only via the natural. Epistemic terms should be analyzed using exclusively non-normative, non-epistemic vocabulary; and epistemic concepts are to be reduced to or explained in terms of non-normative, non-epistemic concepts;

20 A referee for this journal notes that my construal of internalism is consistent with the existence of external requirements for justification and suggests that this is a problem because there are paradigms of internalism that don't make such additional requirements. This is true, but not to the point. It would be a problem with my account if paradigms of internalism fail to satisfy it; it isn't a problem that my account is consistent with further conditions that some paradigmatic theories don't require. Furthermore, one can see how to strengthen the definition of internalism I have here: require that every epistemically relevant aspect of $\mathrm{J}$ be internally accessible (call this 'strong externalism'). Alston's view that a justifier must be accessible will then count as 'internalism' but not 'strong internalism' because it also requires that a justifier be a truthconducive ground (and this property is presumably not introspectively accessible). On the other hand, Chisholm's theory would be a version of 'strong internalism' because his theory requires not only the justifier to be accessible, but the fact that the justifier is sufficient for justification to be accessible too.

I owe this point to William Alston. 
and epistemic properties are reducible to, or supervenient upon, natural properties.

It is by no means obvious that semantic epistemological naturalism is true. One reason for adopting a skeptical position is the nature of epistemic defeat. A justificatory defeater is a proposition or state that makes a belief unjustified which, ceteris paribus, would be justified. As argued in the first section of this paper, any plausible theory of justification must make a place for justificatory defeat. But it is precisely here that trouble brews for the friends of semantic epistemological naturalism. For a no-defeater condition will have to specify the circumstances under which a defeater is potent enough to defeat the prima facie justification of the belief. But the sort of potency here is epistemic. Let's consider an example. I am now looking at my computer keyboard in good light and I have formed the belief that there is a computer keyboard in front of me. For the sake of argument, grant that my belief is prima facie justified. Now do I possess a defeater for it? Well, I do have beliefs that are negatively relevant to its being justified. I know that people sometimes hallucinate without realizing that they are, and I must admit that even if I were hallucinating now I probably would not know it. So this gives me some reason for thinking that my belief is not reliably acquired. But most of us are perfectly willing to suppose that while this is a consideration against my prima facie justification, it is by no means sufficient to void it. Were I justifiably to believe that I had recently taken a drug that would make me hallucinate standard office equipment, my justification would be defeated. Why is my prima facie justification defeated in the second case but not the first? Loosely, in the former instance the evidence that my belief is unreliably produced is very weak; I do not have good reason to believe it. However, the latter case is one in which the evidence of my unreliability is decidedly better. Yet the concept of good reason is epistemic if anything is; indeed to have good reason to believe that $\mathrm{p}$ is sometimes taken to mean none other than one is justified in believing that $\mathrm{p}$. So it looks like the explication of ultima facie justification might well refer to the epistemic. Thus, it might seem that in offering an account of justification, one will have to employ a term, notion, or property, that is thoroughly epistemic; worse still, it might be that the term that figures in the analysandum is the analysans itself.

Of course, I'm not claiming to have demonstrated that there is a difficulty here. The argument I gave in the preceding paragraph is far too sketchy for that. But one who has doubts that there is at least the appearance of a problem would do well to attempt to name a theory of justification in which all of the epistemological terminology has been successfully removed. ${ }^{22}$

22 One might suppose that Goldman's reliabilism in (Goldman 1979) is an example of a semantically naturalized account of justification. But this turns out not to be the case. As discussed in footnote 17 , Goldman attempts to account for defeasibility via avail- 
This is not the place for a detailed discussion of semantic epistemological naturalism, and what its falsity would entail for epistemology. What I want to do here is outline a possible response for the naturalist which makes use of the $\mathrm{p} / \mathrm{u}$ distinction.

As mentioned above, the challenge for the naturalist is to include an account of epistemic defeat as part of her theory of justification without making reference to justification itself. In the abstract, it looks like one could get an account of justification that satisfies semantic epistemological naturalism if one could first offer a naturalistically acceptable account of prima facie justification and then refer to prima facie justification as the only epistemic term of one's account of ultima facie justification. Loosely put, the idea would be to make the primary focus prima facie justification. The no-defeater condition would then be defined as that which, were it conjoined with that which gives one's belief prima facie justification, would make the person's belief not prima facie justified. Of course, this by no means solves the problem, for one still has to offer a plausible account of prima facie justification that satisfies the constraints of semantic epistemological naturalism, and one must construct a plausible no-defeater condition that refers to prima facie justification as the only epistemic property. However, the p/u distinction can help one to see how an account might be constructed that allows the no-defeater clause to make reference to justification without the theory being circular or non-naturalistic.

There is a second way that the p/u distinction might help the cause of semantic epistemological naturalism. As I claimed above, it isn't entirely clear that there is a theory of ultima facie justification that will satisfy the naturalist. If there is no acceptable naturalistic theory of justification, the most likely reason is that the no-defeater clause is inexplicable without making use of epistemic terms. However, even if the no-defeater condition is not natural-

able reliable processes that the agent could have used but didn't. A belief that $\mathrm{p}$ is justified iff it is produced by a reliable cognitive process and there is no other reliable process available to the agent such that had she used it, she would not believe that $p$. The key question here concerns the notion of availability. Goldman realizes that this is potentially problematic. He writes:

"What is it for a process to be available to a cognizer? Were scientific procedures 'available' to people who lived in pre-scientific ages? Furthermore, it seems implausible to say that all 'available' processes ought to be used...” (pp. 189-90). It seems clear that merely having a process 'available,' in a objective sense, is not to have it available in the right way. To say that one must believe that such a process is available is problematic for several reasons, one of which is that it would require everyone to have scores of beliefs about available cognitive processes. It seems that what is necessary is an epistemic notion of availability: a process is available in the required sense only if one has reason to believe that it is available. Hence, we have epistemic vocabulary reintroduced. Also, one should note Goldman's use of 'ought' in the quoted passage. The sense of 'ought' here is epistemic; so if we are to understand his condition as one regarding available processes the agent ought to have used (rather than could have used) then the account's dependence upon epistemic terminology is blatant. 
istically explicable, the prima facie justification condition might be. For example, one might consistently hold a reliabilist account of prima facie justification together with an non-naturalistic account of the no-defeater condition. I am not here advocating such a view, but it might be an attractive fall back position for one sympathetic with semantic epistemological naturalism, who comes to believe that the no-defeater condition resists naturalistic explication. For if I am right in thinking that prima facie justification should be at the center of our theorizing, then finding a naturalistic account of this epistemic property is neither trivial nor unimportant.

\section{Conclusion}

The p/u distinction is helpful not only because it allows us to make sharper distinctions, but more importantly, it helps us focus our attention on the essence of the debate. Since everyone does or at least should recognize the importance of epistemic defeasibility, then every theory will have to make room for defeat; but if that is right, then that aspect of the theory of justification isn't crucial to the individuating of theories. Prima facie justification is where the action is, epistemologically speaking. Therefore, we should carve up the conceptual pie along those lines.

In this paper, I have been concerned to make explicit an epistemic distinction that has been generally recognized, but under-appreciated. Of the countless distinctions in contemporary epistemology, there are very few that can do more to earn their keep. ${ }^{23}$

23 Thanks to William Alston, Robert Audi, Christopher Hill, Louis Pojman, Scott Sturgeon, Mark O. Webb and two anonymous referees for discussion and comments on an earlier draft of this paper. 


\section{REFERENCES}

1. Alston, W. P. 1989. Epistemic Justification: Essays in the Theory of Knowledge. Ithaca, New York: Cornell University Press.

2. BonJour, L. 1985. The Structure of Empirical Knowledge. Cambridge, Massachusetts: Harvard University Press.

3. Chisholm, R. M. 1989. Theory of Knowledge (Third Edition). Englewood Cliffs, New Jersey: Prentice Hall.

4. Foley, R. 1987. The Theory of Epistemic Rationality. Cambridge, Massachusetts: Harvard University Press.

5. Goldman, A. I. 1979. "What is Justified Belief?" in G. Pappas, ed., Justification and Knowledge. Dordrecht, Holland: Reidel Publishing Company.

6. Lewis, C. I. 1946. An Analysis of Knowledge and Valuation. La Salle, Illinois: Open Court Publishing Company.

7. Pollock, J. 1986. Contemporary Theories of Knowledge. Totowa, New Jersey: Rowman \& Littlefield. 